\title{
Women in leadership in Malaysia
}

\begin{abstract}
In this chapter, I analyze women in leadership in Malaysia from historical, political, economic, and cultural perspectives. I discuss women in leadership vis-à-vis women's social status, family roles, and expectations of women in Malaysian society. A critical review of women in leadership roles in Malaysia is presented. Issues on the participation of women in the workforce, gender inequality, women's leadership roles, and work-family relationships are also highlighted against the backdrop of the Malaysian cultural background. I conclude with a discussion of the challenges faced by women who aspire to be leaders in this country within the framework of the government, workplace, community, and family. The review is based on online sources and national and international empirical studies. Recommendations for future research conclude the chapter.
\end{abstract}

